\title{
Contextualizing the Informed Consent Process in Vaccine Trials in Developing Countries
}

Yauba Saidu ${ }^{1 *}$, Aderonke Odutola ${ }^{1}$, James Jafali ${ }^{1}$, Olatunde Ogundare ${ }^{1}$, Archibald Worwui ${ }^{1}$, Gibbi Sey ${ }^{1}$, Vivat Thomas ${ }^{1}$, Elizabeth StanleyBatchilly', Muhammed Afolabi', Olubukola Idoko', Olumuyiwa Owolabi' and Martin Ota OC ${ }^{1,2}$

${ }^{1}$ Vaccinology Theme, Medical Research Council Unit, The Gambia $20^{\text {th }}$ Atlantic Road Fajara, West Africa

${ }^{2}$ Health Systems and Services Cluster, WHO Regional Office for Africa, Djoue-Brazzaville, Congo

\section{Abstract}

Introduction: Most sponsors of clinical trials in Africa propose the use of complicated informed consenting procedures as in developed countries, including the translation of informed consent forms into local languages. Although well intentioned, this practice may be irrelevant and of no added value in settings where local languages are only spoken but not written. Recognizing this challenge, the ethics committee in The Gambia recommend a consent procedure that takes into account these local realities. The objective of this paper was to assess the effectiveness of this new procedure in conveying key trial information among participants in a vaccine trial in The Gambia.

Methods: Consent was obtained from 1200 parents using the new procedure. Comprehension was then assessed using a tool that contained questions on key aspects of the trial.

Results: Although the majority of respondents had no formal education, almost all of them had a sound understanding of the trial. Variables such as age, gender, education, ethnicity and occupation had minimal effect on comprehension.

Discussion and Conclusion: Our data suggest that the new consent procedure is effective in conveying key research information to research participants. The procedure is promising in that it has eliminated the need for repeatedly translating and back-translating informed consents. It also guarantees that the study team expresses research concepts in the same way.

Keywords: Informed consent; Trial information; Vaccine trials; Developing countries; Trial participants; Translation and backtranslation

\section{Introduction}

There has been a spectacular increase in the number of clinical trials in many settings across the developing world [1]. This rise, however, has not been associated with a significant adjustment in key aspects of these trials, especially the procedure for obtaining Informed Consent (IC) $[2,3]$. The IC process is a mandatory requirement in clinical research, and its relevance and specifications are clearly outlined in international legal and ethical guidelines such as the Nuremberg Code [4], The Declaration of Helsinki [5], The Belmont Report [6] and The Council for International Organizations of Medical Sciences (CIOMS) [7]. These guidelines echo the absolute need for investigators to provide potential participants with sufficient information about a trial. These should include the objectives, the study design and procedures, the risk and benefits of participation, their rights as participants, and to allow them adequate time to make a voluntary and informed decision about participation. Provision of this information in a way that the participants fully understand its content is critical in obtaining genuine informed consent from potential participants before they are enrolled in a trial [8].

In practice, however, achieving genuine informed consent continues to be a major challenge in many settings. Indeed, several studies have consistently shown that potential participants have major problems in understanding the basic elements of a research project as outlined on the information sheet even after repeated explanations and questioning [9-14]. Others may have serious misunderstanding including the inability to distinguish between research and clinical practice $[14,15]$, or failure to acknowledge that they are even taking part in a research [16]. Additionally, participants may have the tendency of believing that the trial is principally undertaken for their own benefits rather than for generating new knowledge or as a foundation for future research [17].

These misunderstandings/misconceptions of research are common in developing nations, partly because of factors such as low literacy skills, limited access to health care and lack of familiarity with clinical research and consent procedures $[16,18,19]$. Although the impact of these factors on the informed consent process is well recognized, they are rarely taken into consideration by most sponsors when designing informed consent documents for clinical trials conducted in developing nations; instead most sponsors have the tendency to simply transfer the informed consent process that is applicable in industrialised nations to developing countries [20]. One of such scenarios is when sponsors overload consent forms with information required by the Health Insurance Portability and Accountability Act (HIPAA) [21], and by clauses to limit liability. Although well intentioned, this requirement is rarely applicable in developing countries; it simply makes consent forms unnecessarily lengthy, complex and meaningless to the reader. Consequently, the essential information they contain may

*Corresponding author: Yauba Saidu, Vaccinology Theme, Medical Research Council Unit, The Gambia, 20th Atlantic Road Fajara, PO Box 273 Banjul, the Gambia, West Africa, Tel: +220 38 13922; E-mail: ysaidu@mrc.gm, yaubasaidu@yahoo.com

Received March 21, 2013; Accepted May 28, 2013; Published June 10, 2013

Citation: Saidu Y, Odutola A, Jafali J, Ogundare O, Worwui A, et al. (2013) Contextualizing the Informed Consent Process in Vaccine Trials in Developing Countries. J Clinic Res Bioeth 4: 141. doi:10.4172/2155-9627.1000141

Copyright: $\odot 2013$ Yauba S, et al. This is an open-access article distributed unde the terms of the Creative Commons Attribution License, which permits unrestricted use, distribution, and reproduction in any medium, provided the original author and source are credited. 
Citation: Saidu Y, Odutola A, Jafali J, Ogundare O, Worwui A, et al. (2013) Contextualizing the Informed Consent Process in Vaccine Trials in Developing Countries. J Clinic Res Bioeth 4: 141. doi:10.4172/2155-9627.1000141

Page 2 of 7

paradoxically be misconstrued or lost during the consent process [20], particularly if participants have low literacy skills or limited time to read and understand the information [22]. The process becomes even more complex when some of these sponsors, in wanting to comply with certain standard recommendations [23], request investigators in developing nations to translate IC into local languages, using Arabic or Latin scripts. While this practice may be well intentioned, it may be meaningless in settings where local languages are only spoken and not written, and may end up with participants being presented with informed consent forms that neither they nor other members in their families can read. This may cause the informed consent process to fail, and if this happens, participants' rights may be violated.

These apparent deficiencies prompted some local ethics committees, including in The Gambia, to recommend a new procedure (Figure 1) [24]. In the new procedure, model informed consent forms developed by the sponsor are first reviewed and customized by the investigators using basic language in accordance with local realities. The local version, which must be in English and must not be longer than 4 pages, is then reviewed by the Scientific Coordinating Committee. This committee consists of scientists who are vastly experienced in policies guiding international research in Africa. After a satisfactory review, the committee forwards the proposal to the local ethics committee for further review and approval. Once approved, the investigators and field staff obtaining consent are trained on this English version to be able to interpret the contents verbally into local languages in accordance with regional needs. During the training sessions, the field staff practices the informed consent process in role plays. This should help the staff to internalize the process and master commonly encountered research terms, which have been previously translated into local languages by our Clinical Trials Support Office. These role-plays are audio-recorded and archived in the trial master file. In this paper, we investigated the usefulness of this approach in conveying trial information among participants in a pneumococcal vaccine trial in the Gambia.

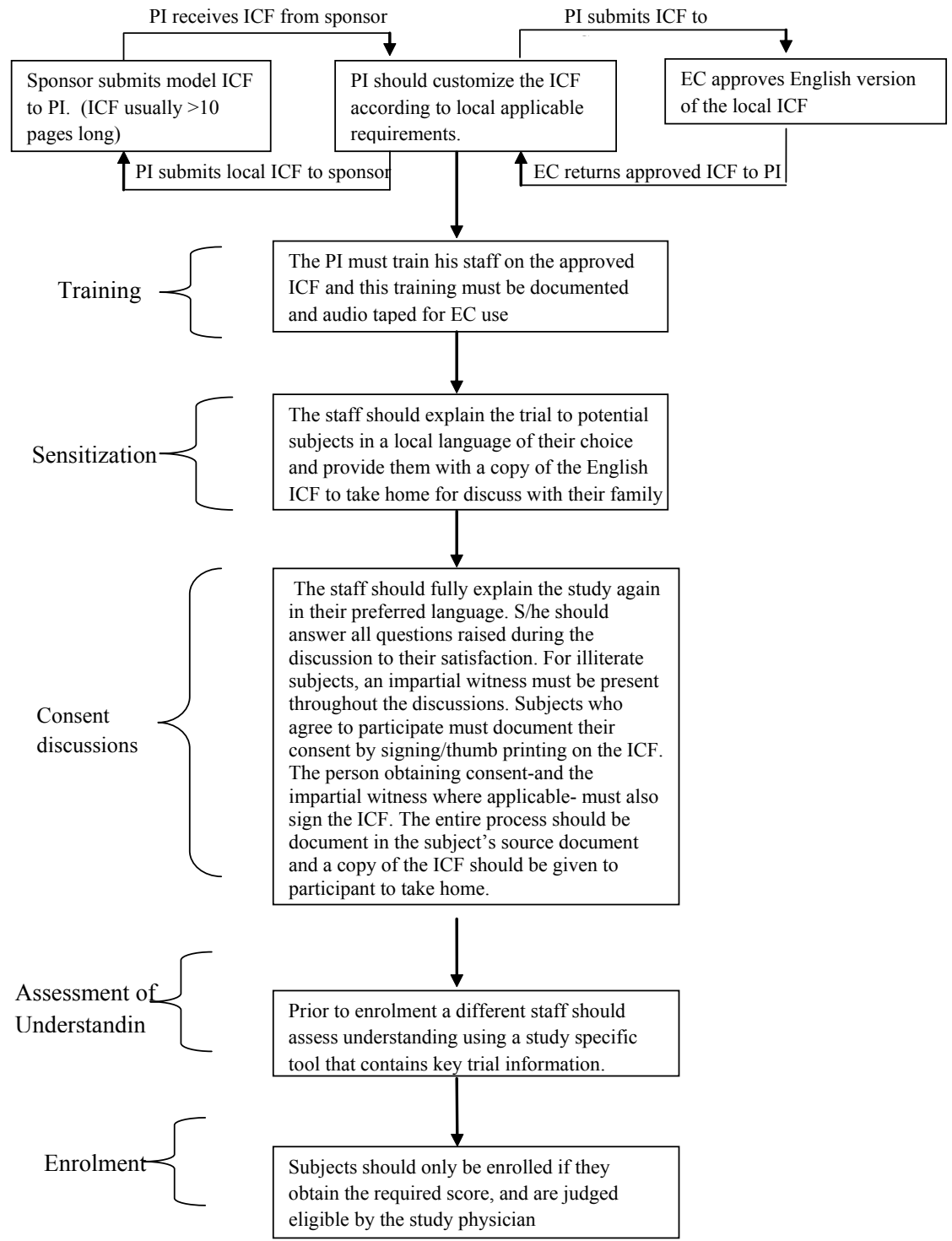

Figure 1: Informed Consent Procedure. EC: Ethics Committee; ICF: Informed Consent Form; PI: Principal Investigator. 


\section{Methods}

\section{Study setting}

The study was conducted in The Gambia, a small West African country that is completely surrounded by Senegal, except for a small coastline on the Atlantic Ocean in the west. The country has limited natural resources and relies on agriculture and local trade for livelihood. In recent years, the economic growth is being driven by expanding banking, tourism and telecommunication sectors. A significant proportion of the population have no formal education and the majority live in rural areas.

Like many Sub-Saharan African countries, The Gambia has a high burden of infectious diseases and these diseases form a major focus of research that is being undertaken by the Medical Research Council Unit (MRC), The Gambia. MRC was established in 1947 by the British Government and has since conducted several major vaccines trials [2528].

\section{Population, sampling and consent discussion}

The study population was drawn from mothers who provided informed consent for their children to participate in a Phase II, randomized, controlled and observer blind trial to evaluate the impact of a combined protein-polysaccharide vaccine on nasopharyngeal carriage of Streptococcus pneumoniae in Gambian infants [29]. A total of 1200 infants were enrolled from July 2011-May 2012 after consent was obtained from their parents. Recruitment was preceded by an extensive community sensitization campaign where the purpose and nature of the trial were first presented to community leaders/chiefs and other interest groups before proceeding to meet individual participants.

Post-natal mothers presenting to specified health centres for the immunization of their new born with Bacille Calmette Guerin, Oral Polio and Hepatitis B vaccines were individually contacted by trained study staff (field workers). At this point, the fieldworkers explained the objectives and nature of the trial to the mothers as outlined in the information sheet in a language that the mothers fully understood. These discussions were done in private and mothers who showed interest in the trial were given study information sheets in English to take home for discussion with their families. In addition, fieldworkers visited interested mothers at their homes to explain the study to their husbands and other family members including grandparents and inlaws. Mothers who agreed-in consultation with other family membersthat the child should participate in the trial were requested to return to the clinic for further discussions. Mothers who returned to the health centre received further explanations, in their preferred language, on all aspects of the trial, including the trial objectives, procedures, randomization, voluntariness, risks and benefits and confidentiality amongst others. At all times during this process, mothers were encouraged to ask questions if anything was unclear to them. Questions that arose during the discussions were answered to their apparent satisfaction by the experienced field staff. For illiterate participants, an impartial witness was present throughout the discussion to attest that the trial was adequately explained to the mothers, and that the information discussed was consistent with that on the information sheet. An additional role of the impartial witness was to provide reassurance that unlettered mothers apparently understood the information and that the consent they provided was free, voluntary and informed. Literate mothers who accepted to join the trial were requested to sign and personally date the IC Form (ICF) while illiterate mothers were requested to thumb print on the ICF in the presence of the impartial witness, who also signed and personally dated the ICF. In both cases, the staff conducting the informed consent also signed and dated the ICF. The entire procedure lasted for about 45-60 minutes and at the end, the participants were given copies of signed/ thumb printed ICFs for their records.

\section{Assessment of understanding of trial information}

In line with our standard operating procedure, an informed consent understanding assessment tool was developed and pre-tested prior to the initiation of the trial. This tool contained nine closed questions on the study's purpose, design, procedures, voluntariness, and confidentiality with an option to answer true or false. This tool was used by a different study staff who did not conduct the consent procedure to assess understanding of key trial information from mothers before their infants were enrolled into the study. For illiterate mothers, the staff administered the questions in their preferred language encircled the responses given by the mothers, while literate mothers were given the questionnaire and instructed to encircle their responses. This assessment was done in the presence of a study physician. A correct response was scored 1 while incorrect answers were scored zero. Participant's score was expressed as percentage of total possible score. Mothers who answered more than seven questions correctly during the first attempt were enrolled into the study while those who missed two or more questions were sent back for consenting desk for a repeat discussion on the study information. . These, mothers were subsequently re-assessed after explanation has been given. If mothers could not still answer all questions after the second attempt, they were not enrolled into the study even if they showed interest in participating in the trial.

\section{Data analysis}

Completed questions were double entered in Open Clinica and the data were processed and analysed using Stata version 12. Accurate scores for understanding were summed up for individual respondent and summary statistics were estimated. We used Chi square tests for association to compare proportions of obtaining 9/9 among different levels of socio-demographic factors. We assessed the associations of age, tribe, education levels, religion, family type and occupation. Further, logistic regression analyses were performed to estimate odds ratios and their $95 \%$ confidence intervals for each factor while mutually adjusting for other factors mentioned above. A two-sided $p$ value $<0.05$ was considered to be statistically significant. Findings are presented in tables and text.

\section{Results}

A total of 1200 mothers provided informed consent for their infants to participate in the clinical trial but 29 (2.4\%) of them were excluded from the analysis because of incomplete demographic data. The sociodemographic characteristics of the remaining 1171 (97.6\%) mothers are presented in Table 1 . The mean age (SD) of these respondents was $27 \pm$ 2.3 years and over half ( $55.2 \%)$ of the respondents were aged between 25 and 36 years. All but one of these mothers (99.9\%) were biological parents of the study participants; $3 \%$ of whom were single parents. The predominant ethnic groups were Mandinka (44.1\%) followed by Jola (19.9\%) then Wolof (12.5\%). An overwhelming majority of them were Muslims (95.3\%). About $90 \%$ of these mothers were unemployed and they came essentially from monogamous families (74.5\%). Ninety one percent of them had access to mobile phone. Approximately $63 \%$ of them had no formal education while the remaining fraction has attended primary school $(17.8 \%)$, secondary school $(20 \%)$ and 


\begin{tabular}{ll}
\hline Variables & $\mathbf{n}(\%)$ \\
\hline Age & \\
<25 & $430(36.82)$ \\
$25-36$ & $645(55.22)$ \\
$>36$ & $93(7.96)$ \\
TRIBE & \\
Mandinka & $515(44.05)$ \\
Wolof & $146(12.49)$ \\
Fula & $116(9.92)$ \\
Jola & $232(19.85)$ \\
Serahule & $38(3.25)$ \\
Manjago & $31(2.65)$ \\
Aku & $1(0.09)$ \\
Serrer & $48(4.11)$ \\
Others & $42(3.59)$ \\
Education & \\
None & $449(38.67)$ \\
Arabic school & $280(24.12)$ \\
Primary school & $196(16.88)$ \\
Secondary school & $233(20.07)$ \\
University & $3(0.26)$ \\
Religion & \\
Christainity & $53(4.54)$ \\
Islam & $1113(95.29)$ \\
Others & $2(0.17)$ \\
Family type & \\
Monogamy & $869(74.46)$ \\
Polygamy & $272(23.31)$ \\
single parent & $26(2.23)$ \\
Occupation & \\
Unemployed & $1033(88.52)$ \\
Trading & $66(5.66)$ \\
Farming & $3(0.26)$ \\
Civil servant & $43(3.68)$ \\
Others & $22(1.89)$ \\
Required Impartial witness & \\
Yes & $977(83.43)$ \\
No & $194(16.6)$ \\
Respondent relationship to infant & \\
Mother & $1170(99.9)$ \\
Aunt & \\
Yes & \\
\hline$\quad$ Tabs telephone & \\
\hline
\end{tabular}

Table 1: Socio-demographic characteristics of study population.

university $(0.2 \%)$. And finally, $83 \%$ of these mothers, including some of those who claimed to have attended secondary school, could not read the information sheet and therefore required an impartial witness during the process.

Regardless of the inability to read the consent forms, most participants were able to respond appropriately to the test questions. Indeed, 90.5\% (1060/1171) of them responded correctly to all 9 questions while the remaining mothers (111/1171) obtained scores in the following order; $4.8 \%(56 / 1171)$ responded correctly to 8 of the 9 questions; $4.2 \%$ (49/1171) obtained a score of 7 on 9 , while five $(0.4 \%)$ mothers responded appropriately to 6 of the 9 questions. Only 1 participant $(0.09 \%)$ obtained a score of $\leq 5 / 9$.

Almost all (99.9\%) of these participants knew that the purpose of the trial was to examine a new vaccine that can prevent pneumonia and meningitis. Similarly, understanding of the study procedures was also high; about 98\% (1150/1171) of mothers knew the required number of study visits. In addition, almost all mothers (1170/1171) were aware that their infants would also receive routine pediatric vaccines. When asked about the quantity and frequency of blood draw, 98.1\% (1149/1171) gave the right response. The proportion of mothers who knew the number of times that nasopharyngeal swabs (or "secretions from the back of the nostrils") will be collected was relatively low (95.4\%) compared to other procedural aspects of the trial. All respondents were aware that participation in the study was completely voluntary and that they were free to decide whether to participate in the study or not. In addition, almost all (99.5\%) of these respondents agreed that they could withdraw from the study at anytime without giving a reason. And finally, 97\% (1141/1171) of these respondents were aware that no other person, apart from the investigators, would be aware about their child's participation in the trial.

Table 2 highlights the association between some selected sociodemographic characteristics with the respondents' ability to respond correctly to all 9 questions. As illustrated, the ability of mothers to obtain a score of 9 decreased as age increased. For instance, mothers in the age group 25-36 years were less likely to obtain score of $9 / 9$ compared to those younger than 25 years (adjusted OR $=0.61,95 \%$ CI 0.39 to 0.95 ; p-value $=0.02$ ). Other socio-demographic factors including mother's education, tribe, occupation and religion did not show any significant difference.

\section{Discussion}

Obtaining genuine informed consent from prospective research participants is a challenge in many settings across the developing world. This difficulty is linked to a combination of factors including high illiteracy rates [30], concerns about signing documents [31] and the approach to decision-making in the research setting [20,32]. These factors may have a direct impact on the entire research process including participants' ability to understand study information that is being disclosed to them $[19,33,34]$. The effect of these factors can, however, be improved if researchers adhere adequately to certain global recommendations on the informed consent process such as the Nuffield Council on Bioethics, CIOMS guidelines, the European Union guideline on clinical trials as well as the recommendations of the National Bioethics Advisory Committee. In the context of the developing world, most of these guidelines recommend researchers to develop culturally appropriate strategies of obtaining informed consent in ways that honour and respect the individuals and societies that participate in clinical research [35]. In line with these recommendations, and in order to overcome some real life challenges associated with the conventional informed consent process used in the industrialized nations, many researchers in SSA have developed dynamic approaches of obtaining informed consent across a variety of social settings [31,36-38]. For instance, Ogobara and his team in Mali have developed well suited, but different, consent procedures for research involving infants and pregnant women as well as those involving the exposure of research participants to disease vectors [38]. These different procedures indicate how the consent process in many SSA settings has to be approached from different angles. And if such approach is properly implemented, community acceptance of the overall research project may be improved [32]. At the same time, the proper implementation can guarantee a high level of understanding of the key research information, including complex research concepts like study design and randomization [15].

In our study we tried another approach whereby IC was shortened 
Citation: Saidu Y, Odutola A, Jafali J, Ogundare O, Worwui A, et al. (2013) Contextualizing the Informed Consent Process in Vaccine Trials in Developing Countries. J Clinic Res Bioeth 4: 141. doi:10.4172/2155-9627.1000141

Page 5 of 7

\begin{tabular}{|c|c|c|c|c|c|}
\hline & & $\mathrm{OR}(95 \% \mathrm{Cl})$ & $P$ value & $\operatorname{aOR}(95 \% \mathrm{Cl})^{*}$ & $P$ value \\
\hline Age & $\mathrm{n} / \mathrm{N}(\%)$ & & & & \\
\hline$<25$ & $396 / 430(92.31)$ & 1 & & 1 & \\
\hline $25-36$ & $569 / 645$ (88.49) & $0.64(0.42 ; 0.98)$ & 0.042 & $0.61(0.39 ; 0.95)$ & 0.029 \\
\hline$>36$ & $81 / 93(88.04)$ & $0.61(0.30 ; 1.26)$ & 0.186 & $0.52(0.24 ; 1.10)$ & 0.087 \\
\hline \multicolumn{6}{|l|}{ TRIBE } \\
\hline Mandinka & $464 / 515(90.45)$ & 1 & & 1 & \\
\hline Wolof & 132/146 (91.03) & $1.07(0.56 ; 2.04)$ & 0.831 & $1.00(0.52 ; 1.91)$ & 0.996 \\
\hline Fula & $105 / 116(90.52)$ & $1.01(0.51 ; 2.00)$ & 0.982 & $0.98(0.49 ; 1.98)$ & 0.959 \\
\hline Jola & $204 / 232(88.31)$ & $0.80(0.49 ; 1.31)$ & 0.374 & $0.76(0.46 ; 1.27)$ & 0.298 \\
\hline Others & $142 / 160(88.75)$ & $0.83(0.47 ; 1.48)$ & 0.531 & $0.84(0.45 ; 1.56)$ & 0.574 \\
\hline \multicolumn{6}{|l|}{ Education } \\
\hline None & $414 / 449(92.41)$ & 1 & & 1 & \\
\hline Arabic school & $252 / 280(90.65)$ & $0.80(0.47 ; 1.36)$ & 0.402 & $0.77(0.44 ; 1.32)$ & 0.338 \\
\hline Primary school & 171/196 (87.69) & $0.76(0.46 ; 1.27)$ & 0.301 & $0.77(0.46 ; 1.29)$ & 0.321 \\
\hline Secondary \& University & 203/236 (86.02) & $0.84(0.45 ; 1.57)$ & 0.593 & $0.80(0.44 ; 1.47)$ & 0.475 \\
\hline \multicolumn{6}{|l|}{ Religion } \\
\hline Christianity & $48 / 53(90.57)$ & 1 & & 1 & \\
\hline Islam & 996/1113 (89.81) & $0.92(0.36 ; 2.35)$ & 0.859 & $0.77(0.28 ; 2.13)$ & 0.62 \\
\hline \multicolumn{6}{|l|}{ Family type } \\
\hline Monogamy & 769/869 (88.9) & & & 1 & \\
\hline Polygamy & $250 / 272(91.91)$ & $1.42(0.87 ; 2.30)$ & 0.157 & $1.40(0.84 ; 2.33)$ & 0.191 \\
\hline \multicolumn{6}{|l|}{ Occupation_ } \\
\hline Unemployed & $930 / 1030$ (90.38) & 1 & & 1 & \\
\hline Trading & 58 /66 (87.88) & $0.77(0.36 ; 1.66)$ & 0.508 & $0.80(0.36 ; 1.75)$ & 0.573 \\
\hline Farming & $37 / 43(86.05)$ & $0.66(0.27 ; 1.59)$ & 0.352 & $1.18(0.43 ; 3.26)$ & 0.746 \\
\hline Others & $20 / 25(80)$ & $0.43(0.16 ; 1.16)$ & 0.095 & $0.38(0.14 ; 1.08)$ & 0.07 \\
\hline
\end{tabular}

OR: Odds Ratio

aOR: Adjusted Odds Ratio

${ }^{*}$ Adjusted for age, education, tribe, family type, religion and occupation

Table 2: Association between selected socio-demographics and mothers' ability to obtain a score of 9/9.

from 18 to four pages in English Language as recommended by our Ethics Committee and explained at four different stages before obtaining consent. In measuring the effectiveness of this approach, this study found that over $90 \%$ of our study population responded appropriately to the questions that indicate adequate comprehension after having received thorough explanation of the trial in their preferred language. Overall, the understanding of the specific items on study related procedures such as the number of clinic visits, quantity and frequency of sample collection, confidentiality, voluntariness and withdrawal were high. This amazing level of understanding fairly correlates with observations from other studies in several SSA countries, including Ghana [39], Mali [15,40], South Africa [41,42], Cote d'Ivoire [43], Uganda [44], Senegal [36] and even in the Gambia [37].

Our findings can be explained by several factors. First, we provided trial information on five separate occasions including two home visits prior to assessment of understanding. Providing the same information in a repeated manner could have enhanced understanding and retention and this could probably account for our observations. Indeed, it has been shown in Haiti that providing participants with trial information on three separate occasion increased their chances of passing an assessment test by four-fold and this was statistically significant when compared to one session $(20 \%$ vs $80 \%$; $\mathrm{p}=0.0002)$ [45]. In addition, other studies have consistently shown that extended consent discussions between participants and study staff [46-48] or repeated assessments [49] significantly increase participants' ability to understand the research project. Even in studies that did not show a significant increase, there was a general trend towards improvement in understanding [50,51]. Secondly, having lengthy discussion in local languages at homes could have also contributed to the observed findings. In Ghana, for instance, a significant proportion of mothers felt that devoting more time to explain the study in local languages at their homes could improve their understanding [39]. Home visits were a particularly important aspect of our survey and discussion took about two hours because this involved presenting the whole study to the father as well as grandparents or other relatives of the family. These home visits engendered more confidence about the trial among family members; the visits also gave us a better understanding of the family's approach to decision-making with regards to participating in clinical research.

With regards to potential predictors of understanding, we found a significant association between younger age and understanding. In other words, younger parents were more likely to obtain better scores than older parents (Table 2) and this is consistent with findings from Ghana [39] and Mali [40]. The reason for this observation is unclear to us at the moment but can partly be explained by the recent introduction of Information and Telecommunication tools and services in our study setting. Younger people turn to have more access to these services than older people and this access may have influence their ability to understand simple messages and concepts. Our hypothesis can be supported by evidence from one study comparing understanding between rural and urban residents in Mali [15]. In this study, the authors found that urban residents demonstrated a significant higher level of understanding compared to rural residents. The major difference in terms of population characteristics was access to IT tools by urban residents.

Secondly, we found no significant association between 
understanding and educational level of respondent (Table 2). This finding seems to run contrary to findings of other studiesthat comprehension improves with increasing level of education $[46,48,49,52]$. On the other hand, our findings are consistent with findings from South Africa, [41], Ghana [39] and Senegal [36]. In line with these studies, our study shows that illiteracy is not an important obstacle to comprehension. This is essentially because informed consent is more of an interactive process, which requires frequent contacts between study staff and participants. Because of this interactive nature, we were more inclined towards delivering research information to all participants in their preferred language irrespective of their educational level. It is also important to note that equating illiteracy to some sort of mental dullness in most parts of SSA might be misleading. This is because lack of education could be for different reasons at different settings. For instance in SSA many intelligent individuals might not be educated because of lack funds, absence of schools or poor accessibility to these institutions (mostly due to distance), cultural reasons (e.g. preference to Arabic schools), or gender, where girls are restricted from going to schools, etc. This clearly contrasts the situation in the west where lack of education could be due to poor mental capacity.

Although our results indicate impressive comprehension of study information by participants, certain limitations must be acknowledged. First, our study was conducted in a setting that has been under intensive research activities for over sixty years. As a result, our study population could have, over the years, gained substantial familiarity with the activities of our institution as well as the consent process, and this may, in a way, explain our findings. However, we feel that this may not be a credible confounder because studies in research settings in Ghana [33] and Kenya [53] have not demonstrated improved understanding of research projects among participants who have been residing in areas under intensive research. Secondly, we evaluated the understanding of our participants immediately after consent discussions. At this point, the information was still fresh in their minds and this could have increased their chances of obtaining the right responses. Thirdly, we used a tool that contains only nine questions addressing key messages in the study information sheet. This limited set of questions may not suffice to address all aspects of our trial, and this setback may grossly underestimate the true level of understanding in our study population. Additionally, our tool contained closed questions, which lead responses to certain direction as opposed to allowing subjects to express their own opinions. Such questions are also an imperfect way of assessing comprehension because they are susceptible to right guesses. Moreover, test questions focussed essentially on major parts of information that usually raise concerns if inadequately explained and understood, such as study procedures, number of clinic visits and bleeds, and purpose of the trial. Furthermore, the reduction in the length of the IS may lead to an unintentional removal of some relevant research information. In addition, the need to conduct extended and repeated discussions and frequent home visits may be logistically challenging and labour intensive, especially for sites with limited resources. The applicability of the procedure in settings with numerous ethnic groups and tribal languages may be logistically challenging. Last but not least, our study did not employ a qualitative instrument that could adequately explore 'actual' understanding of the participants

Notwithstanding these limitations, our research findings suggest that the consent procedure as recommended by the Gambian Government/MRC Laboratories Joint Ethics committee is effective in conveying major study information to prospective trial participants. The procedure is attractive in that it is simple and faster to implement, and has overcome some major challenges including the provision of lengthy and relatively meaningless informed consent forms to trial participants as well as the difficulty in finding qualified and experienced translators.

\section{Conclusion}

Innovative ways of conveying research information that would be culturally appropriate, without compromising understanding of participants in developing countries are needed. Our study shows that shortening the subject information sheet while retaining the key messages relayed at several stages effectively communicated the key study messages.

\section{Conflict of interest}

The authors declare no conflict of interest

\section{Acknowledgements}

The authors are grateful to all the fieldworkers for their major role in providing study information to our research participants. We also thank all the mothers who participated in this study. Our sincere gratitude also goes to Dr Jenny Mueller, for her helpful comments and edits. This study was nested in trial that was sponsored by the Program for Appropriate Technology in Health, US and GlaxoSmithKline Biologicals, Belgium. Therefore, we will like to thank our sponsors for their financial assistance. These sponsors had no role in the design, conduct, analysis and reporting of this consent study. In addition, they had no role in the decision to submit the article. While the assistance of these sponsors have been important, only the authors are responsible for the opinions and interpretations presented.

\section{References}

1. Thiers FA, Sinskey AJ, Berndt ER (2008) Trends in the globalization of clinica trials. Nat Rev Drug Discov 7:13-14.

2. Emanuel EJ, Wendler D, Killen J, Grady C (2004) What Makes Clinical Research in Developing Countries Ethical? The Benchmarks of Ethical Research. Journal of Infectious Diseases 189:930-937.

3. Glickman SW, McHutchison JG, Peterson ED, Cairns CB, Harrington RA et al. (2009) Ethical and scientific implications of the globalization of clinical research. N Engl J Med 360: 816-823.

4. Office for Human Research Protections. Nuremberg Code: Directives for Human Experimentation.

5. World Medical Association. Declaration of Helsinki - Ethical Principles for Medical Research Involving Human Subjects.

6. The Belmont report : ethical principles and guidelines for the protection of human subjects of research.

7. Council for Internation Organization for Medical Sciences. International Ethical Guidelines for Biomedical Research Involving Human Subjects.

8. Emanuel EJ, Wendler D, Grady C (2000) What makes clinical research ethical? JAMA 283: 2701-2711.

9. Joffe S, Cook E, Cleary P, Clark J, Weeks J (2001) Quality of informed consent a new measure of understanding among Research subjects. Journal of the National Cancer Institute 93:139 -1 47

10. Kiguba R, Kutyabami P, Kiwuwa S, Katabira E, Sewankambo NK (2012) Assessing the quality of informed consent in a resource-limited setting: a crosssectional study. BMC Med Ethics 13: 21.

11. Simon C, Zyzanski SJ, Eder M, Raiz P, Kodish ED, et al. (2003) Groups potentially at risk for making poorly informed decisions about entry into clinica trials for childhood cancer. J Clin Oncol 21: 2173-2178.

12. Schats R, Brilstra EH, Rinkel GJ, Algra A, Van Gijn J (2003) Informed consent in trials for neurological emergencies: the example of subarachnoid haemorrhage. J Neurol Neurosurg Psychiatry 74: 988-991.

13. Lynöe N, Sandlund M, Dahlqvist G, Jacobsson L (1991) Informed consent: study of quality of information given to participants in a clinical trial. BMJ 303 : 610-613.

14. Lynöe N, Hyder Z, Chowdhury M, Ekström L (2001) Obtaining informed consen in Bangladesh. N Engl J Med 344: 460-461. 
Citation: Saidu Y, Odutola A, Jafali J, Ogundare O, Worwui A, et al. (2013) Contextualizing the Informed Consent Process in Vaccine Trials in Developing Countries. J Clinic Res Bioeth 4: 141. doi:10.4172/2155-9627.1000141

15. Krosin MT, Klitzman R, Levin B, Cheng J, Ranney ML. Problems in comprehension of informed consent in rural and peri-urban Mali, West Africa. Clinical Trials. 3: 306-313.

16. Kaewpoonsri N OK, Kitayaporn D, Kaewkungwal J, Vijaykadga S, Thamaree S et al. (2006) Factors related to volunteer comprehension of informed consent for a clinical trial. Southeast Asian J Trop Med Public Health 37: 996-1004

17. Mariner WK (2003) Taking Informed Consent Seriously in Global HIV Vaccine Research. Journal of Acquired Immune Deficiency Syndromes 32: 117-123.

18. Manafa O, Lindegger G, ljsselmuiden C (2007) Informed consent in an antiretroviral trial in Nigeria. Indian J Med Ethics 4: 26-30.

19. Mandava A, Pace C, Campbell B, Emanuel E, Grady C (2012) The quality of informed consent: mapping the landscape. A review of empirical data from developing and developed countries. Journal of Medical Ethics 38: 356-365.

20. Krogstad DJ, Diop S, Diallo A, Mzayek F, Keating J, et al (2010) Informed Consent in International Research: The Rationale for Different Approaches. The American Journal of Tropical Medicine and Hygiene 83: 743-747.

21. Kulynych J, Korn D (2003) The New HIPAA (Health Insurance Portability and Accountability Act of 1996) Medical Privacy Rule. Circulation 108: 912-914.

22. Lesley TMB. Examining the readability of patient-informed consent forms Open Access Journal of Clinical Trials 2: 157-162.

23. Internation Conference on Harmonization of the Technical requirements for the Registration of Medicinal Products for Human Use, ICH Tripartate guideline for Good Clinical Practice Guidelines. 1996.

24. The Gambian Government Joint Ethics Committee. L2010.E06, Clarification on ethical issues relevant to the conduct of clinical research projects. Letter to D Jenny Muller, Clinical Trials Support Manager, MRC, The Gambia Unit. 2010.

25. Leach A, Hilton S, Greenwood BM, Manneh E, Dibba B, et al. (1999) An evaluation of the informed consent procedure used during a trial of a Haemophilus influenzae type B conjugate vaccine undertaken in The Gambia, West Africa. Soc Sci Med 48: 139-148.

26. Cutts FT ZS, Enwere G, Jaffar S, Levine OS, Okoko JB, et al. (2005) Efficacy of nine-valent pneumococcal conjugate vaccine against pneumonia and invasive pneumococcal disease in The Gambia: randomised, double-blind, placebocontrolled trial. Lancet 365: 1139-1146.

27. Sow SO, Okoko BJ, Diallo A, Viviani S, Borrow R, et al. (2011)Immunogenicity and safety of a meningococcal A conjugate vaccine in Africans. N Engl J Med 364:2293-2304.

28. Ota MO, Owiafe PK, Donkor S, Owolabi OA, Brittain NJ,et al. (2011) Immunogenicity of the Tuberculosis Vaccine MVA85A Is Reduced by Coadministration with EPI Vaccines in a Randomized Controlled Trial in Gambian Infants. Sci Transl Med 3: 88ra56.

29. Health PfATf. Pneumococcal Vaccine Project.

30. Ota MOC, Idoko OT, Ogundare EO, Afolabi MO. Human immune responses to vaccines in the first year of life: Biological, socio-economic and ethical issues A viewpoint. Vaccine 31: 2483-2488.

31. Abdel-Messih IAE-S, Maged, Crouch, Michael M, Earhart (2008) Developing Cultural Competence and Overcoming Ethical Challenges in the Informed Consent Process: An Experience from Egypt. Journal of Research Administration 39: $33-40$

32. Roberts L (2008) Infectious disease. Clinical trials: dispelling suspicions, building trust in Mali. Science 320: 1714

33. Hill Z, Tawiah-Agyemang C, Odei-Danso S, Kirkwood B (2008) Informed consent in Ghana: what do participants really understand? J Med Ethics 34 48-53.

34. Lynöe N, Hyder Z, Chowdhury M, Ekström L (2001) Obtaining informed consen in Bangladesh. N Engl J Med 344: 460-461.
35. Bhutta ZA (2004) Beyond informed consent. Bull World Health Organ 82: 771 777

36. Préziosi MP, Yam A, Ndiaye M, Simaga A, Simondon F, et al. (1997) Practica experiences in obtaining informed consent for a vaccine trial in rural Africa. N Engl J Med 336: 370-373.

37. Leach A, Hilton S, Greenwood BM, Manneh E, Dibba B, et al. (1999) An evaluation of the informed consent procedure used during a trial of a Haemophilus influenzae type B conjugate vaccine undertaken in The Gambia, West Africa. Soc Sci Med 48: 139-148.

38. Doumbo OK (2005) Global voices of science. It takes a village: medical research and ethics in Mali. Science 307: 679-681.

39. Oduro A, Aborigo R, Amugsi D, Anto F, et al. (2008) Understanding and retention of the informed consent process among parents in rural northern Ghana. BMC Medical Ethics 9: 12.

40. Ellis RD, Sagara I, Durbin A, Dicko A, Shaffer D, et al (2010) Comparing the Understanding of Subjects Receiving a Candidate Malaria Vaccine in the United States and Mali. The American Journal of Tropical Medicine and Hygiene 83: 868-872.

41. Minnies D, Hawkridge T, Hanekom W, Ehrlich R, London L, et al. (2008) Evaluation of the quality of informed consent in a vaccine field trial in a developing country setting. BMC Med Ethics 9: 15 .

42. Moodley K, Pather M, Myer L (2005) Informed consent and participant perceptions of influenza vaccine trials in South Africa. J Med Ethics 31: 727 732.

43. ANRS1201/1202 Ditrame Plus Study Group (2004) Obtaining informed consent from HIV-infected pregnant women, Abidjan, Côte d'Ivoire. AIDS 18 1486-1488.

44. Christine Pace B, Ambrose Talisuna, David Wendler, Faustin Maiso, Fred Wabwire-Mangen, et al. (2005) Quality of Parental Consent in a Ugandan Malaria Study. Am J Public Health 95: 1184-1189.

45. Fitzgerald DW, Marotte C, Verdier RI, Johnson WD Jr, Pape JW (2002) Comprehension during informed consent in a less-developed country. Lance 360: 1301-1302.

46. Flory J EE (2004) Interventions to improve research participants' understanding in informed consent for research: A systematic review. JAMA 292: 1593-1601.

47. Aaronson NK, Visser-Pol E, Leenhouts GH, Muller MJ, van der Schot AC, et a (1996) Telephone-based nursing intervention improves the effectiveness of the informed consent process in cancer clinical trials. Journal of Clinical Oncology 14: $984-996$

48. Kucia AM, Horowitz JD (2000) Is informed consent to clinical trials an "upside selective" process in acute coronary syndromes? Am Heart J 140: 94-97.

49. Chaisson LH, Kass NE, Chengeta B, Mathebula U, Samandari T (2011) Repeated Assessments of Informed Consent Comprehension among HIV Infected Participants of a Three-Year Clinical Trial in Botswana. PLoS ONE 6: e22696.

50. Tindall B, Forde S, Ross MW, Goldstein D, Barker S, et al. (1994) Effects of two formats of informed consent on knowledge amongst persons with advanced HIV disease in a clinical trial of didanosine. Patient Educ Couns 24: 261-266.

51. Benson PR, Roth LH, Appelbaum PS, Lidz CW, Winslade WJ (1988) Information disclosure, subject understanding, and informed consent in psychiatric research. Law Hum Behav 12: 455-475.

52. Davis TC, Berkel HJ, Holcombe RF, Pramanik S, Divers SG (1998) Informed Consent for Clinical Trials: a Comparative Study of Standard Versus Simplified Forms. Journal of the National Cancer Institute 90: 668-674.

53. Molyneux CS, Peshu N, Marsh K (2004) Understanding of informed consent in a low-income setting: three case studies from the Kenyan coast. Social Science \& Medicine 59: 2547-2559. 